Copyright (C) 2020 by Cherkas Global University

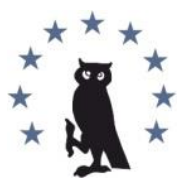

Published in the USA

Zhurnal ministerstva narodnogo prosveshcheniya

Has been issued since 2014 .

E-ISSN: $2413-7294$

2020. $7(2): 40-46$

DOI: $10.13187 /$ zhmnp.2020.2.40

https://zmnp.cherkasgu.press

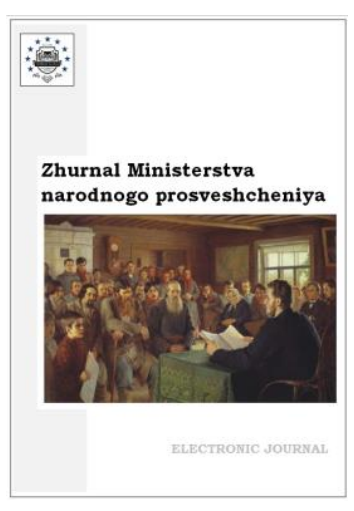

\title{
Digitalization in the Educative Process Specialists for Gas Pumping Stations
}

Igor V. Nungesser a , *, Andrey S. Znamensky a, Alexey V. Malkov a, Sergey A. Ushakov a, Alexander V. Ashikhmin a

a Kalashnikov’s Izhevsk State Technical University, Izhevsk, Russian Federation

\begin{abstract}
Training specialists for the oil and gas industry is a complex process that requires unique equipment and advanced technologies. Gas production and transportation is classified as hazardous production facilities. Therefore, the employees of these enterprises require periodic certification and retraining in the field of industrial safety of hazardous production facilities of the oil and gas industry. Most educational institutions cannot afford to conduct classes on expensive laboratory equipment. Therefore, computer simulators are becoming increasingly popular in the educational process. The paper reviews the most popular computer simulators for training specialists in the oil and gas industry.

Keywords: compressor station, operator of gas pumping unit, computer simulator, mnemonic diagram of the compressor shop.

\section{1. Введение}

Нефтегазовая промышленность России - ведущая отрасль российской промышленности, включающая в себя добычу, переработку, транспортировку и сбыт нефти и газа, а также производство, транспортировку и сбыт нефтепродуктов и газа.

Добыча, транспортировка, хранение и переработка газа - сложнейший процесс, который требует уникального оборудования, самых передовых технологий и знаний. Газ давно не добывают вручную, а значит, каждый сотрудник нефтегазовой компании должен быть высококвалифицированным специалистом, для того, чтобы обслуживать сложное технологическое оборудование.
\end{abstract}

\section{2. Материалы и методы}

Материалами данного исследования послужила нормативная и рекламная интернетдокументация нефтегазовых компаний, связанная с обучением специалистов газоперекачивающих станций. В данном исследовании использовались методы поиска интернет-информации, общетеоретические методы исследования (анализ литературы и нормативной базы, обобщение), эмпирические методы исследования (педагогическое моделирование, эмпатия) и др.

\section{${ }^{*}$ Corresponding author}

E-mail addresses: nungesser_igor@mail.ru (I.V. Nungesser),

andrei.znamensky10@gmail.com (A.S. Znamensky), lexa.malkov.99@mail.ru (A.V. Malkov), mr.sergeyushakov@mail.ru (S.A. Ushakov) 


\section{3. Обсуждение}

В соответствии с Федеральным законом «О промышленной безопасности опасных производственных объектов» (ФЗ № 116-ФЗ от 21.07.1997, ред. от 29.07.2018) предприятия нефтегазовой отрасли относятся к категории опасных производственных объектов. Поэтому, сотрудников, непосредственно связанных с добычей, с транспортом газа требуется проведение периодической аттестации и переподготовки в области промышленной безопасности опасных производственных объектов нефтяной и газовой промышленности.

Инциденты и аварии на опасных производственных объектах развиваются по сложному сценарию, включающему разные типы событий чрезвычайных ситуаций, наиболее часто наблюдаются пожары, взрывы, выбросы опасных веществ. Последствия аварий инцидентов способны нанести ущерб не только предприятию, но и превратить регион в зону экологического бедствия. Анализ материалов расследования аварий на объектах, проведенный Ростехнадзором, показал, что в половине случаев они были вызваны низкой квалификацией персонала (Transas).

Уровень квалификации сотрудника во многом зависит и от учебного заведения, которое он закончил. Поэтому, большое внимание необходимо уделять учебному процессу в высшем учебном заведении и его материально-техническому оснащению при подготовке будущих специалистов нефтяной и газовой промышленности.

В эпоху цифровизации многие учебные заведения отказываются от дорогого по стоимости и обслуживанию лабораторного оборудования в пользу компьютерных тренажеров. Данные программные комплексы призваны решать следующие задачи:

1. изучение оборудования, применяемое в нефтегазовой отрасли;

2. изучение технологического процесса добычи, переработки, транспортировки и сбыта нефти и газа;

3. моделирование и симуляция штатных и не штатных режимов работы предприятия или отдельных его служб и цехов, а также отдельного технологического оборудования;

4. тестирование и отчет о проделанном технологическом процессе студента, которое позволяет преподавателю оценить степень усвоения материала (Logos).

Рабочее место оператора (машиниста технологических компрессоров, машиниста насосной станции и др.) как правило, состоит из монитора, с помощью которого работник получает информацию о ходе технологического процесса, а также клавиатуры и мыши, посредством которых оператор передает системе информацию о своих решениях. Очевидно, что при обучении целесообразно использовать эти же устройства, которые будут использоваться будущими специалистами дальнейшей профессиональной деятельности.

Технологический процесс и устройства, в нем задействованные, как правило, представляются на мониторе оператора в виде мнемосхемы, которая отображает реальное положение работающего оборудования и запорно-регулирующей арматуры в виде различных символов, которые можно разделить на основные классы: компрессор, кран, клапан, контроллер и т. п. Каждый символ несет в себе определенную смысловую нагрузку и обладает набором функций, связанных с ним.

Например, символы устройств, как правило, имеют функции включения или выключения устройства, перевод устройства в автоматический режим управления и другие. Обучаемый должен усвоить эту символику, а также получить и закрепить навыки использования всех основных функций символа каждого типа.

В работе оператора значительную часть занимают стандартные типовые последовательности, такие как пуск или останов различных участков газопровода или перевод их из одного режима работы в другой. Для изучения, запоминания и повторения подобных последовательностей тренажерный комплекс должен включать набор соответствующих упражнений.

С точки зрения оператора технологический процесс представляется множеством компонентов (агрегатов, сосудов, узлов, аппаратов, емкостей и т. п.), каждый из которых представлен на мониторе в виде измерений и показателей состояния. Различные наборы значений измерений и показателей состояния соответствуют различным состояниям газопровода. 
Для поддержания необходимых технологических параметров на магистральном газопроводе сооружаются компрессорные станции (КС) на расстоянии 100-150 км. Они включает в себя группу газоперекачивающих агрегатов (ГПА), технологические системы очистки и охлаждения газа. Приведем упрощенную схему транспортировки газа (Рисунок 1) через компрессорный цех.

Природный газ, поступая с магистрального газопровода в компрессорный цех, вначале проходит через узел очистки, где очищается от различного мусора. После этого газ поступает на компримирование, т.е. сжатие, в газоперекачивающий агрегат (ГПА). Проходя через компрессор ГПА повышается давления газа и его температура, как следствие, увеличивается его объем. В процессе повышения давления технологического газа возрастает его температура. Поэтому после компримирования он поступает в узел охлаждения газа. Далее по выходному шлейфу он возвращается обратно в магистральный газопровод для его дальнейшей транспортировки.

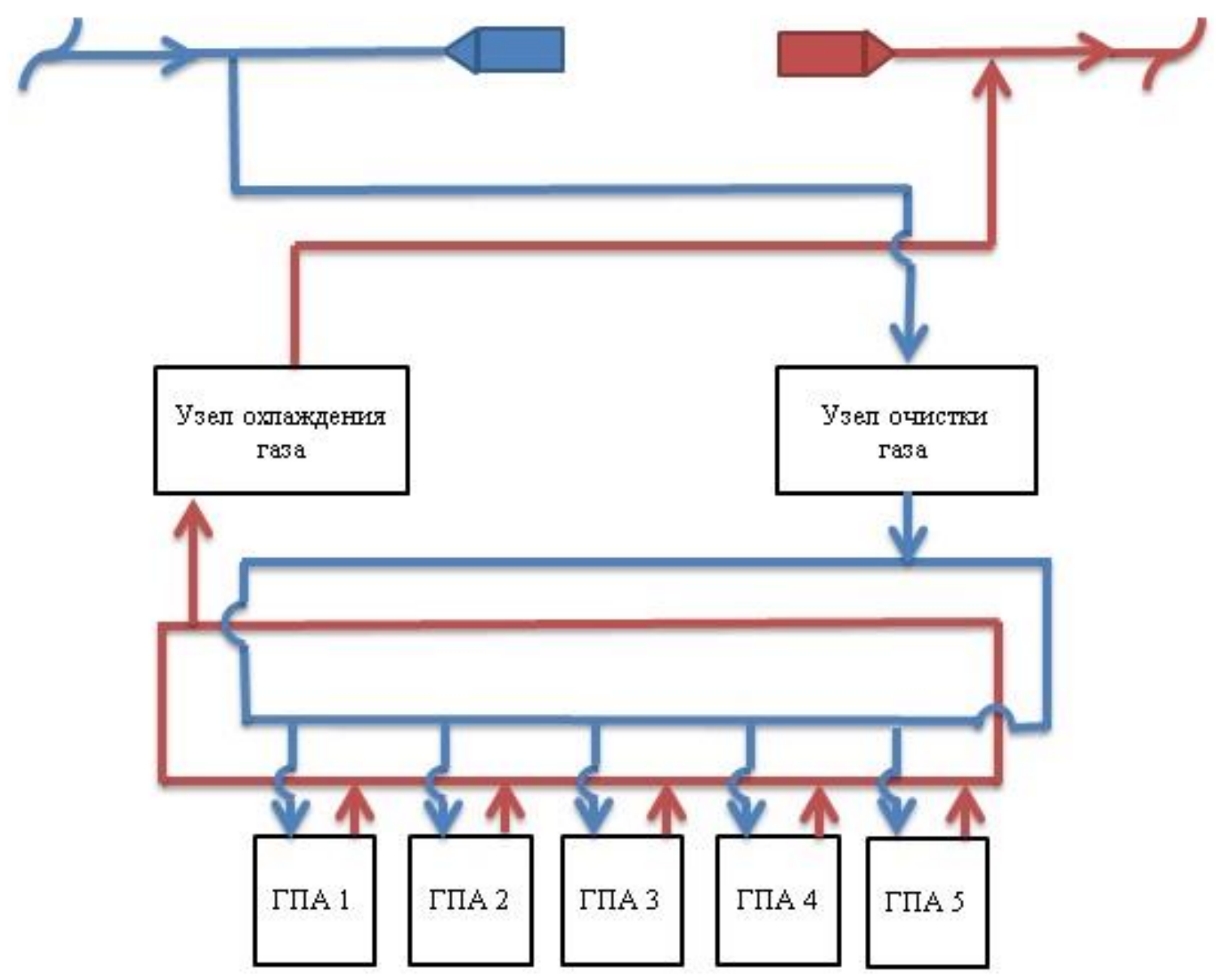

Рис. 1. Схема транспортировки газа через компрессорный цех

\section{4. Результаты}

Использование компьютерного тренажера позволит оператору научиться адекватно оценивать по представленной информации на мнемосхеме состояние отдельных компонентов технологического процесса, а также всего технологического процесса в целом. Таким образом, комплекс упражнений должен содержать задачи по оценке состояния технологического режима, обнаружения признаков неверного поведения оператора, генерации гипотез о причинах неверного поведения, моделирования развития технологического режима в случае бездействия или неверных действий оператора, а также подсказок для приведения режима в штатное состояние (Абрамович, Рейдель, 2016). 
Кроме того, необходимы навыки и умения работы внештатных (аварийных) ситуациях и инцидентах. Если возникновение аварийной ситуации приводит к автоматическому срабатыванию некоторого алгоритма, то необходима отработка навыков поведения оператора после завершения работы данного алгоритма.

Оператор обязан контролировать следующие параметры:

- рабочее давление и температуру газа на входе в компрессорный цех;

- рабочее давление и температуру газа на выходе из компрессорного цеха;

- количество включенных аппаратов в узле очистки газа;

- количество работающих газоперекачивающих агрегатов;

- количество включенных аппаратов в узле охлаждения газа;

- положение запорной арматуры (Трухин).

На сегодняшний день на рынке представлены различные компьютерные тренажеры для нефтегазовой отрасли. По своему функциональному назначению они отличаются тем, что направлены на подготовку и отработку умений по ограниченному перечню задач. Как правило, задач на производстве возникает множество и охватить их все одним компьютерным тренажером невозможно. Наиболее популярные из них представлены ниже:

1. Тренажер ГПУ-16. Поиск неисправностей при обходе оборудования цеха (Рисунок 2) (Professional Group).

Главная Решения

ГПУ-16. Поиск неисправностей при обходе оборудования цеха

- ППу-16. Поиск неисправностей при обходе оборудования чека
ГПУ-16. Поиск неисправностей при обходе оборудования цеха
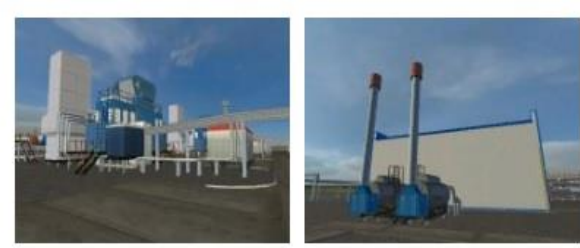

Оборудование:

- Пожарная насосная.

Подогреватели топливного и пүскового газа

Уезл подготовки топливного и импульсного газа (УПтиГ).

- ABO rasa.

Емкости сбора конденсата

Пылеүловители.

Emкости гсM.

Hacochaа ГCM.

- Пожарные гидранты.

Рис. 2. Тренажер ГПУ-16. Поиск неисправностей при обходе оборудования цеха с сайта компании ООО НПФ «ИНФОТЕХ»

Данный тренажер-имитатор включает в себя большинство внутрицехового оборудования (установку очистки газа, отсеки двигателя и нагнетателя ГПА, крановую обвязку ГПА, охлаждения газа и т.д.) и направлен в первую очередь на поиск неисправностей при эксплуатации ГПА.

Преимущества тренажера:

- имеется поиск неисправностей оборудования при эксплуатации ГПА;

- имеет несколько режимов (обучения, контроля, экзамена);

- относительная низкая стоимость для образовательных учреждений.

Недостатки тренажера: 
- узкий перечень отработки действий оператора в штатном режиме;

- представленное оборудование в тренажере ограничено внутрицеховой обвязкой,

- отсутствует узел подключения цеха к МГ;

- относительно высокая стоимость для предприятий нефтегазовой отрасли. (SIKE).

2. Виртуальный тренажерный комплекс для машиниста насосной станции

Тренажерный комплекс (Рисунок 3) предназначен для машиниста насосной станции (установки), который позволяет сформировать навыки безопасного, правильного и быстрого выполнения технологических операций с помощью насосной станции.

\section{ТРЕНАЖЕР-ИМИТАТО}

\section{Машинист насосной станции}
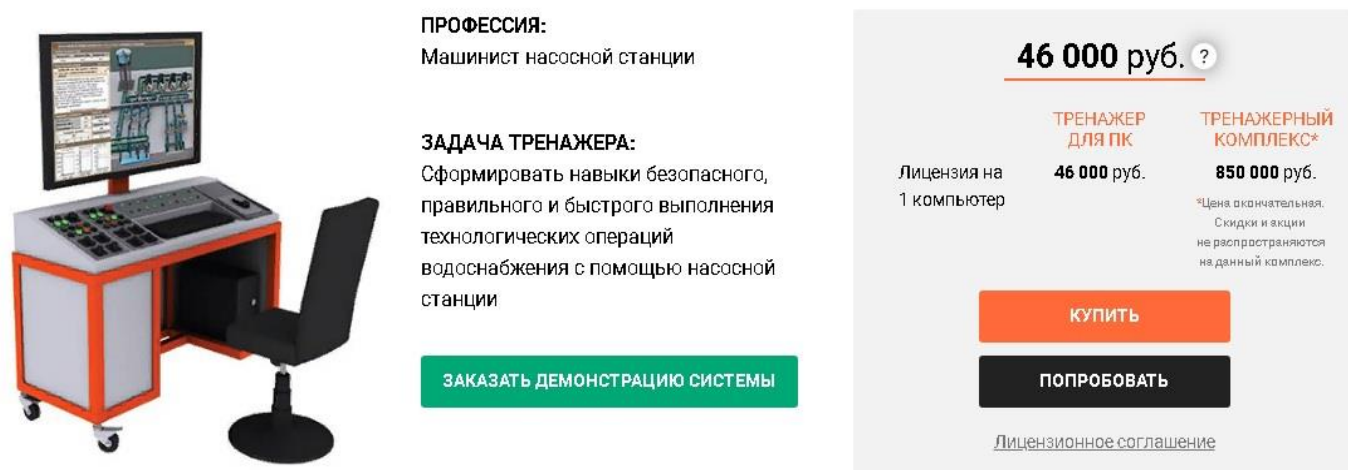

Рис. 3. Виртуальный тренажерный комплекс для машиниста насосной станции с сайта компании ООО «Корпоративные системы Плюс»

Преимущества тренажера:

- широкий перечень тем в обучении (теория и практика);

- имеется выбор приобретения тренажера для ПК или целого тренажерного комплекса;

Недостатки тренажера:

- узкий перечень отработки действий машиниста в не штатном (аварийном) режиме;

- относительная средняя стоимость установки тренажера на 1 компьютер.

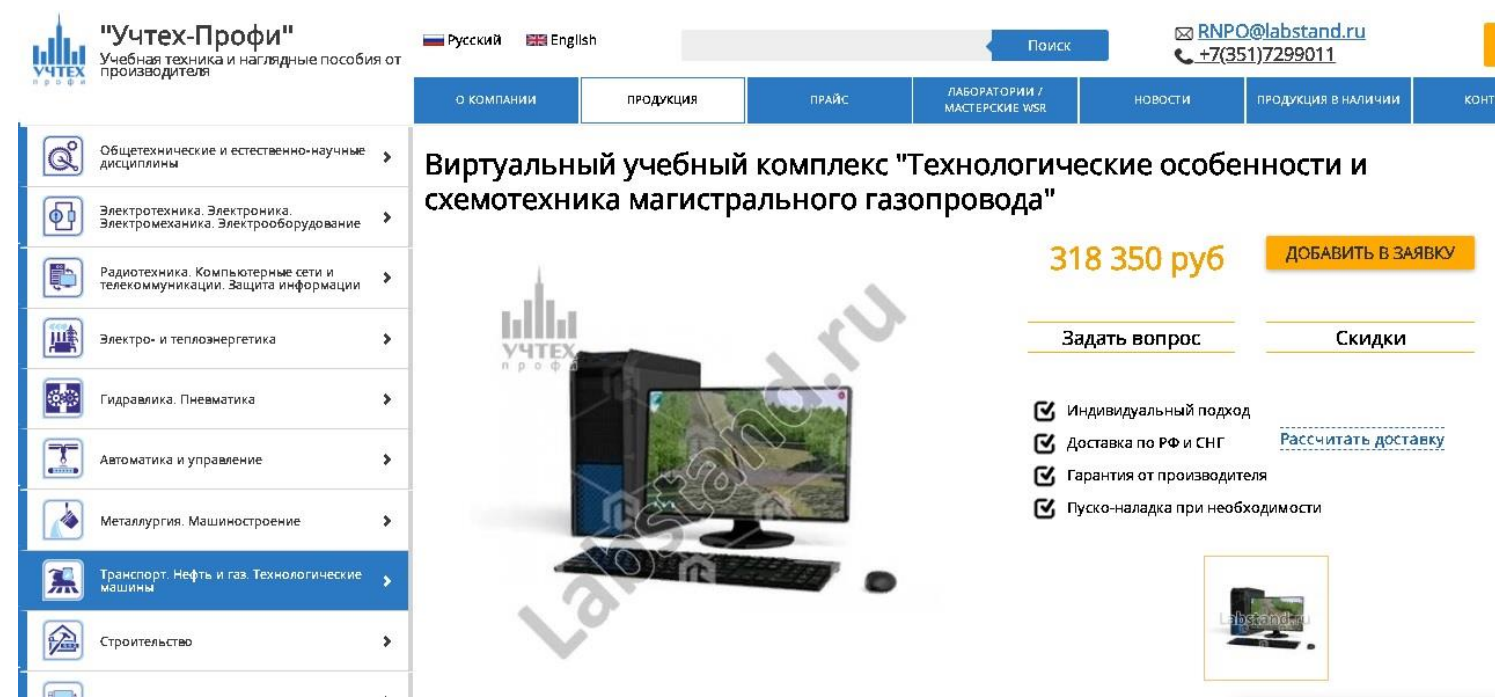

Рис. 4. Виртуальный учебный комплекс «технологические особенности и схемотехника магистрального газопровода 
3. Виртуальный учебный комплекс «технологические особенности и схемотехника магистрального газопровода (Учтех-Профи).

Учебный комплекс (Рисунок 4) специализирован на обучении работников газовой отрасли. Позволяет наглядно отображать принцип работы деталей и узлов оборудования, а также изучать технологические особенности, осуществлять изучение схемотехники и проводить мониторинг состояния во время работы оборудования.

Преимущества тренажера:

- широкий перечень тем в обучении (теория, лабораторные работы и практика).

Недостатки тренажера:

- узкий перечень отработки действий оператора в не штатном (аварийном) режиме;

- относительная высокая стоимость учебного комплекса;

- не предусмотрена возможность приобретения учебного комплекса без оборудования (ПК, монитора, клавиатуры и мыши).

\section{4. Заключение}

Таким образом, проведенный анализ существующих компьютерных тренажеров для подготовки операторов нефтегазового направления выявил ряд преимуществ и недостатков. Так же установлено, что в свободном доступе такие тренажеры отсутствуют, а имеющиеся платные версии или их разработка стоят от нескольких десятков тысяч до нескольких миллионов рублей. В связи с этим в учебных заведения существует необходимость в создании собственного компьютерного тренажера для обучения студентов инженерных специальностей.

\section{Список литературы}

Абрамович, Рейдель, 2016 - Абрамович В.В., Рейдель Л.Б. Интерактивные тренажеры и их значение в учебном процессе // Научный журнал NovaInfo. №41-1. (дата обращения: 10.02.2016).

Трухин - Трухин A.B. Анализ существующих в РФ тренажерно-обучающих систем. Институт дистанционного образования Томского государственного университета (ИДО ТГУ). [Электронный ресурс]. URL: https://ido.tsu.ru/ .ru/about/

Учтех-Профи - ООО НПП «Учтех-Профи». [Электронный ресурс]. URL: http://labstand

Logos - Computer Training Systems for Russians armored vehicles. [Электронный ресурс]. URL: http://logos.mephi.ru

Professional Group - OOO НПФ «ИНФОТЕХ». [Электронный ресурc]. URL: https://www. professionalgroup.ru

SIKE - OOO «Корпоративные системы Плюс». [Электронный ресурс]. URL: http:// e-learn.sike.ru/

Transas - Группа компаний Транзас. Электронные технологии. [Электронный ресурс]. URL: http://www.transas.ru

\section{References}

Abramovich, Reidel', 2016 - Abramovich, V.V., Reidel', L.B. (2016). Interaktivnye trenazhery $\mathrm{i}$ ikh znachenie $\mathrm{v}$ uchebnom protsesse [Interactive simulators and their importance in the educational process]. Nauchnyi zhurnal NovaInfo. 41-1. (date of access: 10.02.2016). [in Russian]

Logos - Computer Training Systems for Russians armored vehicles. [Electronic resource]. URL: http://logos.mephi.ru [in Russian]

Professional Group - OOO NPF “INFOTEKh". [Electronic resource]. URL: https://www. professionalgroup.ru [in Russian]

SIKE - OOO "Korporativnye sistemy Plyus". [Electronic resource]. URL: http:// e-learn.sike.ru/ [in Russian]

Transas - Gruppa kompanii Tranzas. Elektronnye tekhnologii [Transas Group of Companies. Electronic technologies]. [Electronic resource]. URL: http://www.transas.ru [in Russian]

Trukhin - Trukhin, A.V. Analiz sushchestvuyushchikh v RF trenazherno-obuchayushchikh system [Analysis of the existing training and training systems in the Russian Federation]. Institut 
distantsionnogo obrazovaniya Tomskogo gosudarstvennogo universiteta (IDO TGU). [Electronic resource]. URL: https://ido.tsu.ru/ [in Russian]

Uchtekh-Profi - OOO NPP «Uchtekh-Profi». [Electronic resource]. URL: http://labstand.ru /about/ [in Russian]

\section{Цифровизация в процессе подготовки специалистов газоперекачивающих станций}

Игорь Владимирович Нунгессер а, *, Андрей Сергеевич Знаменский а, Алексей Валерьевич Малков ${ }^{\text {, }}$ Сергей Алексеевич Ушаков ${ }^{\text {, }}$ Александр Владимирович Ашихмин а

а Ижевский государственный технический университет имени М.Т. Калашникова, Ижевск, Российская Федерация

Аннотация. Подготовка специалистов для нефтегазовой отрасли является сложным процессом, который требует уникального оборудования, передовых технологий. Добыча и транспортировка газа относится к опасным производственным объектам. Поэтому, для сотрудников данных предприятий требуется проведение периодической аттестации и переподготовки в области промышленной безопасности опасных производственных объектов нефтяной и газовой промышленности. Большинство учебных заведений не могут себе позволить занятия проводить на дорогостоящем лабораторном оборудовании. Поэтому в учебном процессе всё большую популярность приобретают компьютерные тренажеры. В работе проведен обзор наиболее популярных компьютерных тренажеров для подготовки специалистов нефтегазовой отрасли.

Ключевые слова: компрессорная станция, оператор газоперекачивающего агрегата, компьютерный тренажер, мнемосхема компрессорного цеха.

\footnotetext{
* Корреспондирующий автор

Адреса электронной почты: nungesser_igor@mail.ru (И.В. Нунгесcep), andrei.znamensky10@gmail.com (А.С. Знаменский), lexa.malkov.99@mail.ru (А.В. Малков), mr.sergeyushakov@mail.ru (С.А. Ушаков)
} 